\title{
Far-infrared rays enhance mitochondrial biogenesis and GLUT3 expression under low glucose conditions in rat skeletal muscle cells
}

\author{
Yelim Seo', Young-Won Kim', Donghee Lee', Donghyeon Kim², Kyoungseo Kim², Taewoo Kim², Changyeob Baek², \\ Yerim Lee ${ }^{2}$, Junhyeok Lee ${ }^{2}$, Hosung Lee ${ }^{2}$, Geonwoo Jang ${ }^{2}$, Wonyeong Jeong ${ }^{2}$, Junho Choi ${ }^{2}$, Doegeun Hwang ${ }^{2}$, Jung \\ Soo Suh ${ }^{2}$, Sun-Woo Kim ${ }^{3}$, Hyoung Kyu Kim ${ }^{3}$, Jin Han ${ }^{3}$, Hyoweon Bang ${ }^{1}$, Jung-Ha Kim ${ }^{4}$, Tong Zhou ${ }^{5, *}$, and Jae-Hong Ko ${ }^{1, *}$ \\ Departments of ${ }^{1}$ Physiology and ${ }^{2}$ Medicine, College of Medicine, Chung-Ang University, Seoul 06974, ${ }^{3}$ Cardiovascular and Metabolic Disease Center, SMART \\ Marine Therapeutics Center, Inje University, Busan 47392, ${ }^{4}$ Department of Family Medicine, College of Medicine, Chung-Ang University Hospital, Seoul 06973, \\ Korea, ${ }^{5}$ Department of Physiology and Cell Biology, University of Nevada, Reno School of Medicine, Reno, NV 89557, USA
}

\section{ARTICLE INFO}

Received December 10, 2020

Revised December 25, 2020

Accepted December 27, 2020

\section{*Correspondence}

Jae-Hong Ko

E-mail: akdongyi01@cau.ac.kr

Tong Zhou

E-mail: tongz@med.unr.edu

Key Words

Glucose

Glucose transporter type 3

Infrared rays

Mitochondrial biogenesis

Radiation
ABSTRACT Far-infrared rays (FIR) are known to have various effects on atoms and molecular structures within cells owing to their radiation and vibration frequencies. The present study examined the effects of FIR on gene expression related to glucose transport through microarray analysis in rat skeletal muscle cells, as well as on mitochondrial biogenesis, at high and low glucose conditions. FIR were emitted from a bio-active material coated fabric (BMCF). L6 cells were treated with 30\% BMCF for 24 $\mathrm{h}$ in medium containing 25 or $5.5 \mathrm{mM}$ glucose, and changes in the expression of glucose transporter genes were determined. The expression of GLUT3 (SIc2a3) increased 2.0-fold ( $p<0.05$ ) under $5.5 \mathrm{mM}$ glucose and 30\% BMCF. In addition, mitochondrial oxygen consumption and membrane potential $\left(\Delta \Psi_{m}\right)$ increased 1.5- and 3.4-fold ( $p<$ 0.05 and $p<0.001$ ), respectively, but no significant change in expression of Pgc-1a, a regulator of mitochondrial biogenesis, was observed in $24 \mathrm{~h}$. To analyze the relationship between GLUT3 expression and mitochondrial biogenesis under FIR, GLUT3 was down-modulated by siRNA for $72 \mathrm{~h}$. As a result, the $\Delta \Psi_{\mathrm{m}}$ of the GLUT3 siRNA-treated cells increased 3.0-fold ( $p<0.001$ ), whereas that of the control group increased 4.6fold ( $p<0.001$ ). Moreover, Pgc-1a expression increased upon 30\% BMCF treatment for $72 \mathrm{~h}$; an effect that was more pronounced in the presence of GLUT3. These results suggest that FIR may hold therapeutic potential for improving glucose metabolism and mitochondrial function in metabolic diseases associated with insufficient glucose supply, such as type 2 diabetes.

\section{INTRODUCTION}

Far-infrared rays (FIR) are electromagnetic waves ranging between 3 and $100 \mu \mathrm{m}$ that hold the ability to penetrate up to $2.5 \mathrm{~cm}$ into the skin, affecting muscles, as well as blood and lymph vessels, owing to their radiation and vibration frequency. FIR have a vibrational frequency of 3-100 $\mathrm{THz}$ that transfers to atoms and molecular structures [1] and, importantly, can induce a muscle wound healing effect [2,3]. A previous work confirmed that FIR can enhance mitochondrial copy number, oxygen consumption, as well as genes related to apoptosis and mitophagy in rat muscle tissues [4]. These results suggest that FIR activates the PINK1mediated mitochondrial quality control pathway and mitochondrial biogenesis, which consequently increases the efficiency of

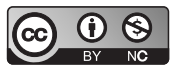

This is an Open Access article distributed under the terms of the Creative Commons Attribution Non-Commercial License, which permits unrestricted non-commercial use, distribution, and reproduction in any medium, provided the original work is properly cited. Copyright @ Korean J Physiol Pharmacol, pISSN 1226-4512, elSSN 2093-3827
Author contributions: Y.S., Y-W.K., and D.L. designed the experiments and interpreted the data. D.H., J.C., D.K., K.K., J.L., C.B., W.J., H.L., G.J., T.K., Y.L., S-W.K., J.S.S., and Y.S. performed the experiments. H.K.K., J.H., and H.B. analyzed the data. Y.S. and J.K. wrote the manuscript. T.Z. and J-H.K. supervised the study. 
oxidative respiration in skeletal muscle. However, the effects of FIR on mitochondrial morphology and membrane potential remain to be validated, and the precise mechanism of FIR-mediated upregulation of mitochondrial function is unclear.

Mitochondria are cellular organelles present in high numbers in the brain, liver, heart, and muscles. They use glucose and fatty acids to synthesize ATP as an energy source for cellular function [5]. Mitochondrial dysfunction is implicated in cardiovascular disease, aging, metabolic disease, cancer, and degenerative diseases [6,7]. Indeed, diabetes is closely related to increased reactive oxygen species production, which is directly responsible for mitochondrial dysfunction, and is one of the key factors underlying the pathological mechanism of diabetic synovial stenosis [8]. Type 2 diabetes mellitus is a condition characterized by metabolic imbalance associated with impaired mitochondrial ATP levels [9]. Due to the close relationship with energy-consuming diseases, research on the development of targeted therapeutics that can directly control mitochondrial function is being actively conducted $[10,11]$.

Glucose transport across the plasma membrane is fundamental to mammalian energy metabolism and is mediated by tissuespecific glucose transporter proteins in the cell membrane [12]. Several studies have highlighted the expression of multiple glucose transporters in the same tissue for regulation of glucose and energy homeostasis [13]. Two main types of glucose carriers exist, namely sodium-glucose linked transporters and glucose transporters (GLUTs). Based on sequence similarity, GLUT proteins are classified into Class 1, comprising the well-characterized glucose transporters (GLUT1-4, 14), Class 2 (GLUT5, 7, 9, 11), and Class 3 (GLUT6, 8, 10, 12, 13) [14,15]. Of the many glucose transporters, GLUT1, GLUT3, and GLUT4 are expressed in rat L6 skeletal muscle cells [16], a cell line that retains many properties of skeletal muscle [17,18]. In cells such as muscle, the transport of glucose across the plasma membrane limits its availability $[19,20]$. Recent research showed that reduced mitochondrial ATP production due to insulin resistance in skeletal muscle is accompanied by a functional reduction in Class 1 GLUTs [14]. Thus, it has been suggested that GLUTs are closely related to changes in mitochondrial function.

The purpose of this study was to demonstrate whether FIR could increase intracellular transport of glucose and promote mitochondrial energy metabolism, thereby improving intracellular glucose deficiency conditions such as occurs in type 2 diabetes, resulting in therapeutic effects.

\section{METHODS}

\section{FIR fabric}

The FIR fabric samples were provided by Ventex Co. (Seoul, Korea). The bio-active materials coated fabric (BMCF) contained over 30 kinds of minerals, including $\mathrm{SiO}_{2}, \mathrm{Mg}, \mathrm{Al}_{2} \mathrm{O}_{3}, \mathrm{Na}, \mathrm{Ca}$, and $\mathrm{Fe}_{2} \mathrm{O}_{3}$. The fabric was irradiated with FIR and the Korea FarInfrared Association (Seoul, Korea) confirmed that the emission rate between 5 and $20 \mu \mathrm{m}$ was $89.5 \%$. The emission energy was $3.45 \times 10^{2} \mathrm{~W} / \mathrm{m}^{2} \cdot \mu \mathrm{m}$ (issue number KFI-789) at $37^{\circ} \mathrm{C}$. In the current study, we used BMCF that emitted $0 \%$ and $30 \%$ FIR. No abnormal skin reactions of any kind were observed during the safety evaluation of the BMCF.

\section{Cells}

Rat skeletal muscle L6 cells were purchased from the Korean Cell Line Bank (Seoul, Korea) and cultured in Dulbecco's modified Eagle medium (DMEM) supplemented with 25 or $5.5 \mathrm{mM}$ glucose (L001-05 or L001-02; WELGENE, Gyeongsan, Korea), and containing $10 \%$ fetal bovine serum and $1 \%$ penicillin/streptomycin [21,22]. The cells were used between passage 29 and 33. For FIR radiation conditions, $0 \%$ and $30 \%$ BMCF was attached inside the culture dish at a distance of $1 \mathrm{~cm}$ from the cells [23], followed by incubation at $37^{\circ} \mathrm{C}$ in $5 \% \mathrm{CO}_{2}$ for 24 and $72 \mathrm{~h}$. The experimental design is shown in Supplementary Fig. 1.

\section{GLUT3 siRNA treatment}

L6 cells were cultured and left to stabilize in DMEM plus 25 $\mathrm{mM}$ glucose for $24 \mathrm{~h}$, before sub-culturing in $5.5 \mathrm{mM}$ glucose medium. GLUT3 siRNA (Slc2q3-rat-282; GenePharma, Shanghai, China) was then administered together with INTERFERin transfection reagent (Polyplus Transfection Inc., Strasbourg, France) at a final concentration of $10 \mathrm{nM}$ siRNA.

\section{Quantitative real-time polymerase chain reaction (qRT-PCR)}

mRNA expression and mitochondrial DNA copy number (mtDNA-CN) were measured using the Fast Start DNA Master SYBR Green I kit and the LightCycler 2.0 system (Roche, Basel, Switzerland). All primers used for qPCR analysis are described in Supplementary Table 1. Gapdh was used as the internal control. For mtDNA-CN assessment, the expression of the mitochondrial displacement loop (D-loop) in total genomic DNA was also corrected for based on Gapdh levels. Each reaction mixture contained $0.8 \mu \mathrm{MgCl}_{2}$ (final concentration: $3 \mathrm{mM}$ ), $0.2 \mu \mathrm{l}$ of each forward and reverse primer (final concentration: $0.2 \mu \mathrm{M}$ ), $1 \mu \mathrm{l}$ of 10× LightCycler DNA Master SYBR Green I, and $1 \mu \mathrm{l}$ cDNA template in a final volume of $10 \mu \mathrm{l}$ in distilled water. mRNA expression was determined based on $\mathrm{Ct}$ values using the $2^{-\Delta \Lambda C t}$ reference method [24].

\section{Reverse transcription PCR (RT-PCR)}

Pgc-la mRNA expression was measured using the AccuPower 
Taq PCR Premix (Bioneer, Deajeon, Korea) and a C1000 Thermal Cycler (Bio-Rad, Hercules, CA, USA). Gapdh was used as the internal control. The primers used for RT-PCR are described in Supplementary Table 1 . The reaction mixture contained $1 \mathrm{U}$ Taq DNA polymerase, $250 \mu \mathrm{M}$ dNTPs, $1 \times$ reaction buffer (with 1.5 $\mathrm{mM} \mathrm{MgCl}$ ), $0.2 \mu \mathrm{l}$ of each forward and reverse primer (final concentration: $0.2 \mu \mathrm{M}$ ), and $1 \mu \mathrm{l}$ template cDNA.

\section{Mitochondrial oxygen consumption}

Mitochondrial oxygen consumption was measured according to the method described by Frezza et al. [25]. Measurement of the respiratory control rates was performed in a solution containing $20 \mathrm{mM}$ ADP, $5 \mathrm{mM}$ glutamate, $2.5 \mathrm{mM}$ malate, and MIR05 buffer $\left(0.5 \mathrm{mM}\right.$ EGTA, $3 \mathrm{mM} \mathrm{MgCl}_{2}-6 \mathrm{H}_{2} \mathrm{O}, 60 \mathrm{mM}$ K-lactobionate, $20 \mathrm{mM}$ taurine, $10 \mathrm{mM} \mathrm{KH} \mathrm{PO}_{4}, 20 \mathrm{mM}$ HEPES, $110 \mathrm{mM}$ sucrose, $1 \mathrm{~g} / \mathrm{L} \mathrm{BSA}, \mathrm{pH}$ 7.1). Oxygen consumption was carried out in a NeoFox chamber and was monitored with NeoFox viewer software v. 2.30 (Ocean Optics Inc., Dunedin, FL, USA). The respiratory control ratio (RCR) was calculated according to the oxygen consumption values in the presence (state 3 ) and absence (state 4) of ADP [26].

\section{$\Delta \Psi_{\mathrm{m}}$ and mitochondrial mass measurement}

$\Delta \Psi_{\mathrm{m}}$ was measured using tetramethylrhodamine ethyl ester (TMRE; excitation/emission $=549 / 574 \mathrm{~nm}$; Abcam, Cambridge, UK). L6 cells were treated with TMRE at a final concentration of $100 \mathrm{nM}$ and allowed to react at $37^{\circ} \mathrm{C}$ for $30 \mathrm{~min}$ to induce TMER accumulation in the mitochondria [27]. To measure mitochondrial mass, cells were stained with acridine orange 10-nonyl bromide (NAO; Invitrogen, Waltham, MA, USA) at a final concentration of $2.5 \mu \mathrm{M}$ in phosphate-buffered saline (PBS) solution [28], incubated in the dark at $37^{\circ} \mathrm{C}$ for $30 \mathrm{~min}$, and then washed twice with PBS. TMRE and NAO fluorescence for each group were observed under an LSM 700 confocal microscope (Carl-Zeiss, Oberkochen,
Germany). Mitochondrial mass measurements were performed at an excitation wavelength of $488 \mathrm{~nm}$, and the emission of NAO was measured beyond $585 \mathrm{~nm}$. The TMRE and NAO mean intensity of the region of interest (ROI) were measured in each cell and analyzed by Image J software (NIH, Bethesda, MD, USA) [29].

\section{Statistical analysis}

All collected data were analyzed using IBM SPSS Statistics v. 20.0 (IBM Corp., Armonk, NY, USA). Statistical significance was determined using the Student's t-test and one-way and two-way ANOVA. A p-value $<0.05$ was considered statistically significant. The Student's t-test was used to evaluate mRNA relative expression, mtDNA-CN relative ratio, and $\mathrm{RCR} / \mathrm{mtDNA}-\mathrm{CN}$ ratio data. The one-way and two-way ANOVA were used for assessing TMRE and NAO fluorescence intensity per cell area ratio data.

\section{RESULTS}

\section{GO pathways related to glucose transport and regulation are stimulated by FIR in rat skeletal muscle}

Microarray data extracted from a previous study [23] were assembled for $\mathrm{GO}$ map analysis. We confirmed that pathways related to glucose transport and regulation were stimulated by FIR in rat skeletal muscle (Fig. 1). Response to glucose (GO:0009749, $\mathrm{p}<0.001)$, regulation of glucose transport (GO:0010827, $\mathrm{p}<0.01$ ), glucose transport (GO:0015758, $\mathrm{p}<0.05)$, positive regulation of glucose transport (GO:0010828, $\mathrm{p}<0.05)$, regulation of glucose import (GO:0046324, $\mathrm{p}<0.05$ ), glucose import (GO:0046323, $\mathrm{p}=0.057)$, cellular response to glucose stimulus (GO:0071333), cellular glucose homeostasis (GO:0001678), positive regulation of glucose import (GO:0046326), glucose metabolic process (GO:0006006), glucose homeostasis (GO:0042593), and regulation of glucose metabolic process (GO:0010906) were all activated

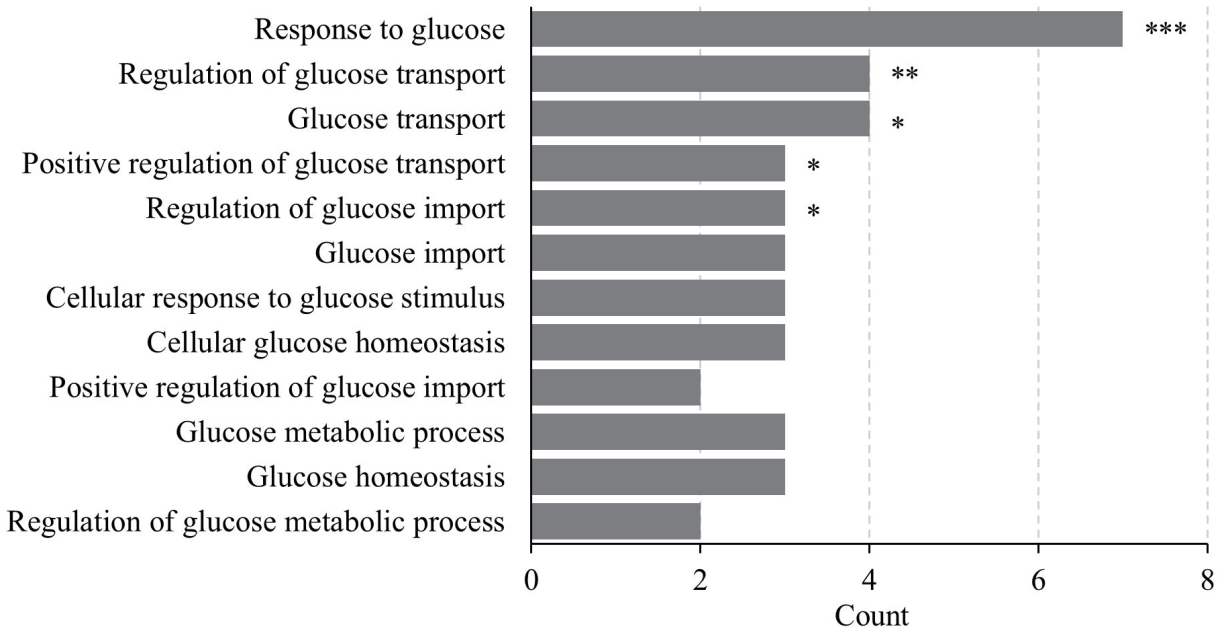

Fig. 1. Gene ontology (GO) enrichment analysis. The bar graph indicates the number of differently expressed genes in $\mathrm{GO}$ terms associated with glucose from bio-active materials coated fabricworn rat skeletal muscle. The nine GO biological process terms ranked with the highest $p$-value are shown. GO functional analysis was based on gomap stat. ${ }^{*} p<0.05,{ }^{* *} p<0.01,{ }^{* * *} p<0.001$ vs. control group. 
by FIR. These results confirm that FIR hold potential to affect glucose metabolism.

\section{FIR regulates GLUT3 expression in L6 cells under low glucose conditions}

To assess the effect of FIR on glucose metabolism, L6 cells were exposed to BMCF for $24 \mathrm{~h}$ under 25 and $5.5 \mathrm{mM}$ glucose conditions. Interestingly, genes related to glucose metabolism identified in the microarray data (Table 1) were found to be altered in the in vitro assay. Among these, a 2.0-fold significant increase was only observed in the expression of GLUT3 (also known as Slc2a3) in the presence of $30 \% \mathrm{BMCF}$ and $5.5 \mathrm{mM}$ glucose compared with that of the non-treated group ( $\mathrm{p}<0.05$, Fig. $2 \mathrm{~B}$ ). No significant differences were observed in the expression levels of other genes related to glucose metabolism, such as G6pd, Ugdh, Uggt2, Slc2a5, Slc2a10, Slc35d2, Slc37a2, RGD1559971, Slc2a13, Soga1, Gfod2, Gdpgp1, Slc2a9, Slc2a12, Tgds, Ugcg, Gpi, Naglt1, Uggt1, Slc2a8, RGD1304770, Slc2a7, Ugp2, H6pd, Slc37a4, Slc5a2, G6pc, RGD1563815, RGD1561777, Slc2a6, G6pc3, Slc5a1, Slc5a4, Slc37a1, and Gfodl (data not shown).

Given the observed increase in GLUT3 expression by 30\% BMCF under low glucose conditions, the expression of GLUT1, 2, and, 4 were also evaluated in a similar experimental setting. GLUT1 expression increased 1.7-fold in the presence of $5.5 \mathrm{mM}$ glucose compared to that of the $25 \mathrm{mM}$ glucose condition, but

Table 1. List of glucose transport-related genes from microarray data of BMCF-worn rat skeletal muscle

\begin{tabular}{|c|c|c|c|c|}
\hline Gene symbol & Gene accession & Fold change & p-value & Gene description \\
\hline G6pd & NM_017006 & 1.717 & 0.865 & Glucose-6-phosphate dehydrogenase \\
\hline Ugdh & NM_031325 & 1.518 & 1.000 & UDP-glucose 6-dehydrogenase \\
\hline Uggt2 & XM_006252469 & 1.359 & 1.000 & UDP-glucose glycoprotein glucosyltransferase 2 \\
\hline Slc2a5 & NM_031741 & 1.212 & 1.000 & $\begin{array}{l}\text { Solute carrier family } 2 \text { (facilitated glucose/fructose transporter), } \\
\text { member } 5\end{array}$ \\
\hline Slc2a10 & NM_001108963 & 1.199 & 1.000 & Solute carrier family 2 (facilitated glucose transporter), member 10 \\
\hline Slc $35 d 2$ & NM_001106098 & 1.138 & 1.000 & $\begin{array}{l}\text { Solute carrier family } 35 \text { (UDP-GlcNAc/UDP-glucose transporter), } \\
\text { member D2 }\end{array}$ \\
\hline Slc37a2 & NM_001191994 & 1.138 & 1.000 & Solute carrier family 37 (glucose-6-phosphate transporter), member 2 \\
\hline Slc2a3 & NM_017102 & 1.110 & 1.000 & Solute carrier family 2 (facilitated glucose transporter), member 3 \\
\hline RGD1559971 & XM_006223919 & 1.089 & 1.000 & Similar to $\mathrm{Na}^{+}$dependent glucose transporter 1 \\
\hline Slc2a13 & NM_133611 & 1.082 & 1.000 & Solute carrier family 2 (facilitated glucose transporter), member 13 \\
\hline Soga1 & XM_001067659 & 1.059 & 1.000 & Suppressor of glucose, autophagy associated 1 \\
\hline Gfod2 & NM_001107421 & 1.055 & 1.000 & Glucose-fructose oxidoreductase domain containing 2 \\
\hline Gdpgp1 & XM_001066043 & 1.047 & 1.000 & GDP-D-glucose phosphorylase 1 \\
\hline Slc2a9 & NM_001191551 & 1.024 & 1.000 & Solute carrier family 2 (facilitated glucose transporter), member 9 \\
\hline Slc2a12 & NM_001107451 & 1.005 & 1.000 & Solute carrier family 2 (facilitated glucose transporter), member 12 \\
\hline Tgds & NM_001107286 & 1.001 & 1.000 & TDP-glucose 4,6-dehydratase \\
\hline Ugcg & NM_031795 & -1.002 & 1.000 & UDP-glucose ceramide glucosyltransferase \\
\hline Gpi & NM_207592 & -1.005 & 1.000 & Glucose-6-phosphate isomerase \\
\hline Naglt1 & NM_176080 & -1.011 & 1.000 & $\mathrm{Na}^{+}$dependent glucose transporter 1 \\
\hline Uggt1 & NM_133596 & -1.016 & 1.000 & UDP-glucose glycoprotein glucosyltransferase 1 \\
\hline Slc2a8 & NM_053494 & -1.029 & 1.000 & Solute carrier family 2, (facilitated glucose transporter) member 8 \\
\hline RGD1304770 & NM_001134547 & -1.042 & 1.000 & Similar to $\mathrm{Na}^{+}$dependent glucose transporter 1 \\
\hline Slc2a7 & XM_006225659 & -1.050 & 1.000 & Solute carrier family 2 (facilitated glucose transporter), member 7 \\
\hline Ugp2 & NM_001024743 & -1.058 & 1.000 & UDP-glucose pyrophosphorylase 2 \\
\hline H6pd & NM_001106698 & -1.058 & 1.000 & Hexose-6-phosphate dehydrogenase (glucose 1-dehydrogenase) \\
\hline Slc37a4 & NM_031589 & -1.080 & 1.000 & Solute carrier family 37 (glucose-6-phosphate transporter), member 4 \\
\hline Slc5a2 & NM_022590 & -1.084 & 1.000 & Solute carrier family 5 (sodium/glucose cotransporter), member 2 \\
\hline G6pc & NM_013098 & -1.085 & 1.000 & Glucose-6-phosphatase, catalytic subunit \\
\hline RGD1563815 & NM_001127556 & -1.114 & 1.000 & Similar to sodium-glucose cotransporter-like 1 \\
\hline RGD1561777 & XM_008773019 & -1.141 & 1.000 & Similar to $\mathrm{Na}^{+}$dependent glucose transporter 1 \\
\hline Slc2a6 & NM_001106562 & -1.191 & 1.000 & Solute carrier family 2 (facilitated glucose transporter), member 6 \\
\hline G6pc3 & NM_176077 & -1.221 & 1.000 & Glucose 6 phosphatase, catalytic, 3 \\
\hline Slc5a1 & NM_013033 & -1.252 & 1.000 & Solute carrier family 5 (sodium/glucose cotransporter), member 1 \\
\hline Slc5a4 & NM_001106383 & -1.253 & 1.000 & Solute carrier family 5 (glucose activated ion channel), member 4 \\
\hline Slc37a1 & NM_001011944 & -1.295 & 1.000 & Solute carrier family 37 (glucose-6-phosphate transporter), member 1 \\
\hline Gfod1 & NM_001170334 & -1.462 & 1.000 & Glucose-fructose oxidoreductase domain containing 1 \\
\hline
\end{tabular}

BMCF, bio-active materials coated fabric. 
A

GLUT1 (Slc2al)

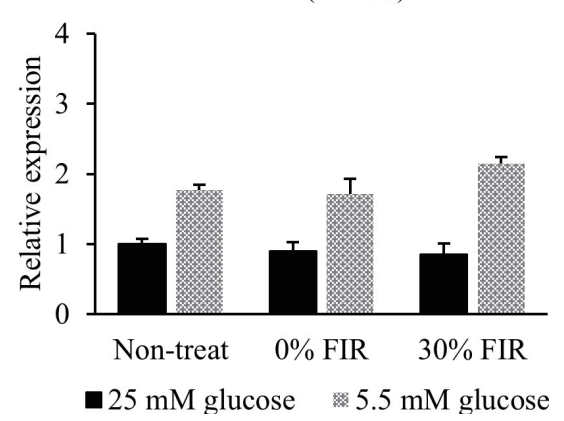

B

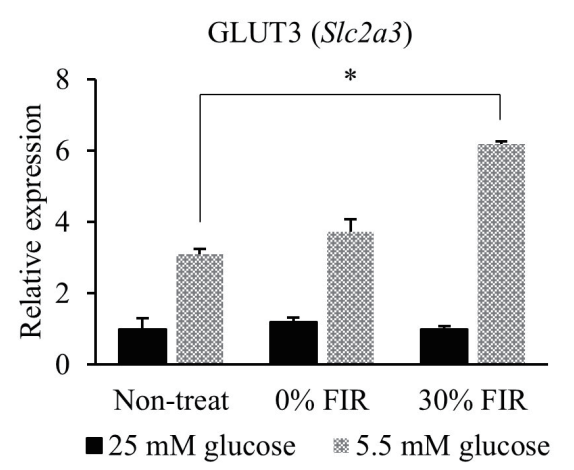

C

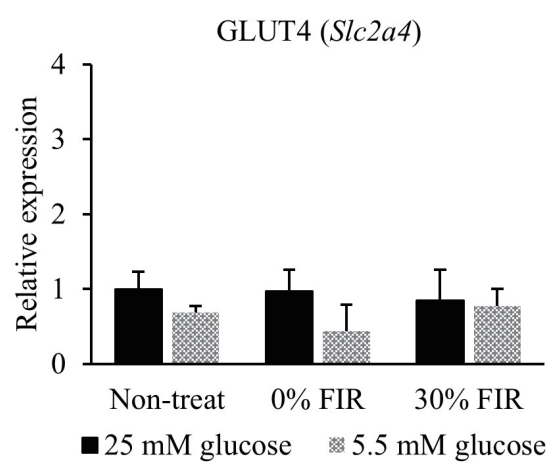

Fig. 2. Far-infrared rays (FIR) alter the mRNA expression of glucose transporter class 1 members. (A) GLUT1 (SIc2a1) (B) GLUT3 (SIc2a3), and (C) GLUT4 (Slcea4) expression was analyzed under 25 and $5.5 \mathrm{mM}$ glucose conditions, and upon bio-active materials coated fabric treatment for $24 \mathrm{~h}$ by quantitative real-time polymerase chain reaction. ${ }^{*} \mathrm{p}<0.05 \mathrm{vs}$. control group.

no significant change in its expression was observed following $30 \%$ BMCF (Fig. 2A). In addition, no significant difference was observed in GLUT4 expression between 25 and $5.5 \mathrm{mM}$ glucose conditions following treatment with 30\% BMCF (Fig. 2C). GLUT2 levels in L6 cells were very low and thus could not be compared for each glucose condition following BMCF treatment (data not shown).

\section{FIR improve mitochondrial biogenesis}

Changes in the mtDNA-CN in L6 cells following incubation with 25 or $5.5 \mathrm{mM}$ glucose plus BMCF treatment for $24 \mathrm{~h}$ were assessed. The mtDNA-CN increased 1.7- and 1.3-fold in the 25 and $5.5 \mathrm{mM}$ glucose conditions ( $\mathrm{p}<0.05$ ), respectively, compared to the non-treated control (Fig. 3A). Next, changes in mitochondrial oxygen consumption in relation to the change in mtDNA$\mathrm{CN}$ were determined to evaluate mitochondrial ATP production ability. The results indicated a 1.2- and 1.5-fold increase in ATP production ability of mitochondria under $30 \% \mathrm{BMCF}$ and 25 and $5.5 \mathrm{mM}$ glucose conditions $(\mathrm{p}<0.05$ and $\mathrm{p}<0.01)$, respectively, compared to the non-treated control (Fig. 3B). In addition, TMRE fluorescence tended to increase upon treatment with 30\% BMCF (Fig. 3C). In particular, by analyzing the TMRE fluorescence intensity ROI, the $\Delta \Psi_{\mathrm{m}}$ was found to be significantly increased by 3.4-fold following 30\% BMCF compared to the non-treated control ( $\mathrm{p}<0.001$, Fig. 3D). However, no significant differences in Pgc-1a expression were observed in the $5.5 \mathrm{mM}$ glucose and $30 \%$ BMCF compared to the non-treated control (Fig. 3E).

\section{Activation of mitochondrial biogenesis by FIR is more pronounced in the presence of GLUT3}

The correlation between increased GLUT3 expression and the improvement in mitochondrial biogenesis under $5.5 \mathrm{mM}$ glucose and FIR treatment was evaluated through gene silencing of GLUT3. The normal control (without siRNA) and GLUT3 siRNA groups were treated with FIR fabric for $72 \mathrm{~h}$, as GLUT3 silencing was not confirmed until $72 \mathrm{~h}$ (data not shown); TMRE and $\mathrm{NAO}$ fluorescence intensity increased in both groups (Fig. 4A, B). Moreover, the ROI calculation of TMRE confirmed that the normal GLUT3 control cells exhibited a 4.2-fold higher fluorescence intensity compared with that of the non-treated group following $72 \mathrm{~h}$ of $30 \%$ BMCF treatment $(\mathrm{p}<0.001)$, while cells silenced GLUT3 showed a 3.0-fold increase in TMRE intensity ( $\mathrm{p}<0.001$, Fig. 4C). The ROI calculation of NAO further confirmed that the control cells exhibited higher fluorescence intensity than that of the non-treated group following $72 \mathrm{~h}$ of $30 \%$ BMCF (5.7-fold increase, $\mathrm{p}<0.001$ ), and the GLUT3 siRNA group showed a 3.6fold increase $(\mathrm{p}<0.001)$. Overall, in 30\% BMCF conditions, the TMRE and NAO intensity of L6 cells reduced GLUT3 decreased 1.4-fold ( $\mathrm{p}=0.056$ ) and 1.6-fold $(\mathrm{p}<0.01)$, respectively, compared to that of the control group (Fig. 4D). In addition, Pgc-la expression increased following 30\% BMCF treatment in both the control and GLUT3 siRNA groups (Fig. 4E).

\section{DISCUSSION}

Here, we aimed to assess changes in glucose transporter expression and mitochondrial biogenesis following exposure to FIR under high and low glucose levels. In fact, $5.5 \mathrm{mM}$ glucose is usually considered a normal glucose serum concentration and corresponds with a low glucose culture medium in vitro. A glucose concentration of $20 \mathrm{mM}$ in vitro corresponds with a high glucose culture medium and is comparable to a hyperglycemic environment that can be found in vivo, notably in diabetic patients [22]. In summary, GLUT3 expression was significantly increased by treatment with BMCF for $24 \mathrm{~h}$ at low glucose levels. Further, the ratio of the mitochondrial function index RCR per mtDNA-CN also increased significantly, as well as the $\Delta \Psi \mathrm{m}$. In addition, $P g c_{-}$ 1a expression increased following 30\% BMCF treatment for 72 h. Taken together, these results demonstrate that FIR effectively 
A

-25 mM glucose $5.5 \mathrm{mM}$ glucose

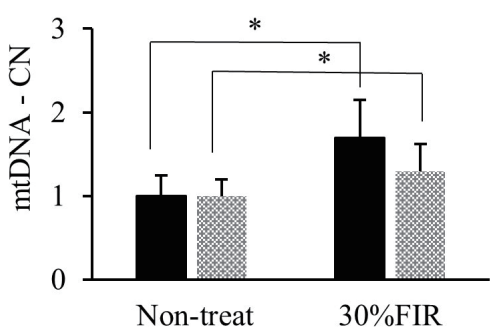

C

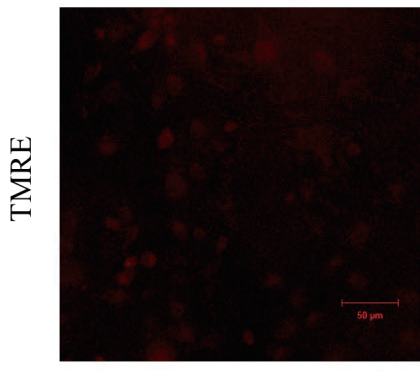

Non-treat

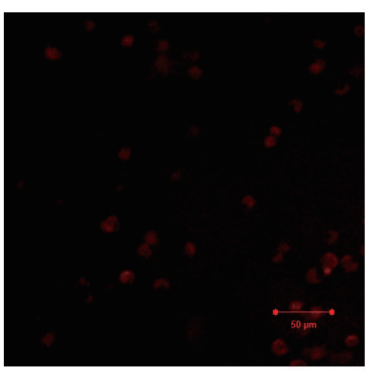

$0 \%$ FIR

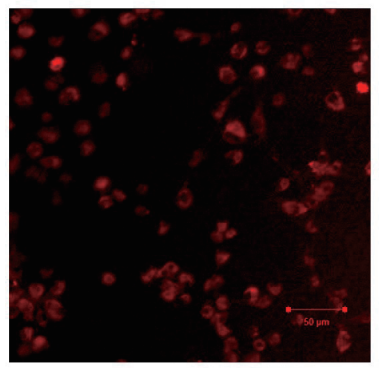

$30 \%$ FIR
D

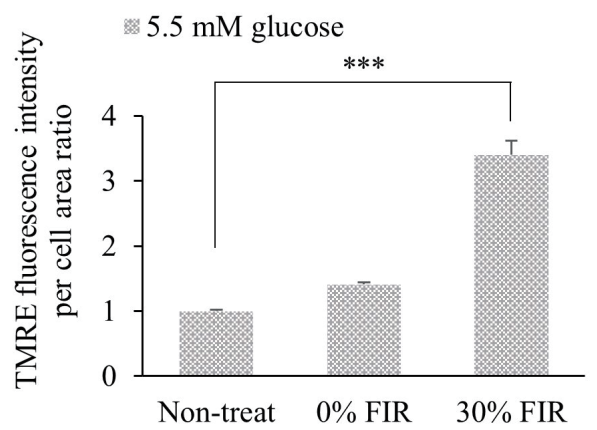

E

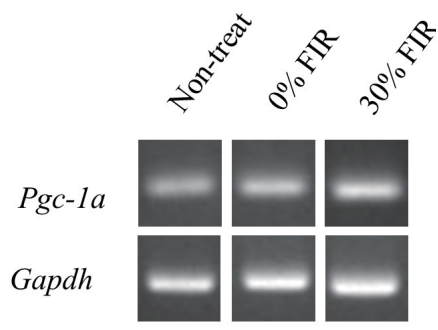

Fig. 3. Far-infrared rays (FIR) effectively activate mitochondrial biogenesis. Changes in (A) mitochondrial DNA copy number (mtDNA-CN) and (B) respiratory control ratio (RCR) per mtDNA-CN ratio under $25 \mathrm{mM}$ and $5.5 \mathrm{mM}$ glucose conditions. (C) Mitochondrial membrane potential $\left(\Delta \Psi_{m}\right)$ was determined by measuring TMRE (tetramethylrhodamine, ethyl ester) fluorescence under $5.5 \mathrm{mM}$ glucose conditions by confocal microscopy (scale bar $=50 \mu \mathrm{m}$ ). (D) TMRE region of interest fluorescence intensity per cell area ratio measurement using Image $J$. (E) Pgc-1a expression was analyzed by reverse transcription polymerase chain reaction. ${ }^{*} p<0.05,{ }^{* *} p<0.01,{ }^{* * *} p<$ 0.001 vs. control group. activate mitochondrial biogenesis and GLUT3 expression at low glucose concentrations.

In our previous study, microarray analysis revealed that mRNA expression in rat muscle cells was stimulated by FIR radiation in a dose-dependent manner at $10 \%$ and 30\% BMCF [23]. Additional analysis of genetic data through GO analysis confirmed the possibility that FIR could affect glucose metabolism (Fig. 1). The present study explored further the impact of FIR on the expression of genes associated with glucose metabolism under high and low glucose conditions in rat skeletal muscle cells (L6). The expression of GLUT3, which is abundant in neurons and is known to transport glucose into cells under hypoglycemic or ischemic conditions [30], tended to increase under $5.5 \mathrm{mM}$ glucose conditions compared with that under $25 \mathrm{mM}$ glucose. In addition, GLUT3 expression was significantly increased (2.0-fold) upon FIR treatment compared with that of the non-treated group (Fig. 2B). GLUT1 [31] is widely distributed in red blood cells and the heart, where it facilitates glucose transport into cells indepen- dently of an insulin signal [32]. The expression of GLUT1 in this study showed a tendency to increase in response to $5.5 \mathrm{mM}$ glucose compared that at $25 \mathrm{mM}$ as seen for GLUT3, but no change in expression was observed following 30\% BMCF treatment (Fig. 2A). In addition, the expression of GLUT4, which is abundant in muscle and adipocytes where it transports glucose in response to insulin [32,33], was not significantly different between the two concentrations of glucose tested nor following 30\% BMCF treatment (Fig. 2C). Given the importance of GLUT3 in neurons [34] and muscle development [35], it is important to characterize the mechanisms that regulate its expression. These observations suggest that FIR specifically stimulate the expression of GLUT3, the product of which transports glucose into cells at low glucose concentrations, independent of insulin. In L6 myotubles, insulin stimulates glucose transport through translocation of the glucose transporters GLUT1, GLUT3, and GLUT4 from intracellular stores to the plasma membrane [36]. It has been proposed that GLUT3 may play an important role in glucose metabolism in 
A
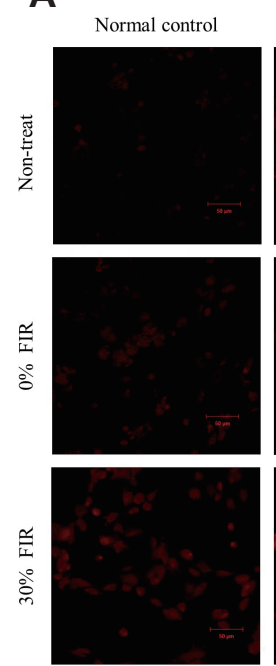

TMRE
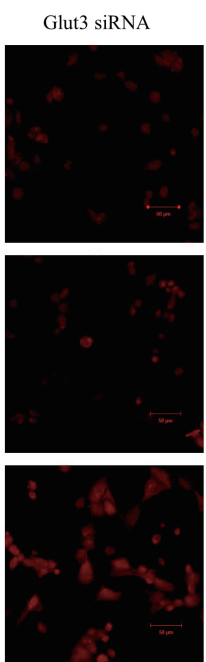

B
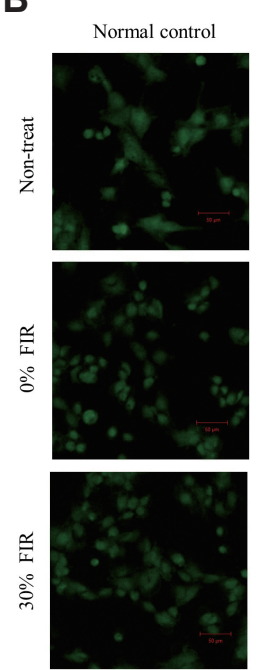

NAO Glut3 siRNA
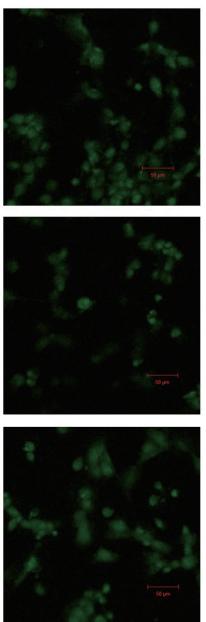

C

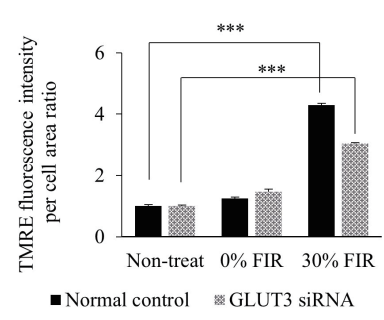

E

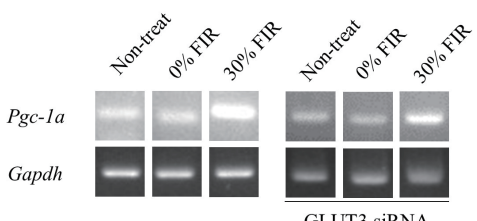

Fig. 4. Far-infrared rays (FIR) activate mitochondrial biogenesis at low glucose concentrations via GLUT3. The control and GLUT3 siRNA groups were treated with bio-active materials coated fabric for $72 \mathrm{~h}$ under 25 or $5.5 \mathrm{mM}$ glucose conditions. (A) Mitochondrial membrane potential $\left(\Delta \Psi_{\mathrm{m}}\right)$ as determined by TMRE (tetramethylrhodamine, ethyl ester) fluorescence and (B) confirmation of mitochondrial mass by measurements of NAO (acridine orange 10-nonyl bromide) fluorescence using confocal microscopy (scale bar $=50 \mu \mathrm{m}$ ). (C) TMRE and (D) NAO region of interest fluorescence intensity per cell area ratio. (E) Pgc-1a expression was performed by reverse transcription polymerase chain reaction. ${ }^{* * *} p<0.001$ vs. control group; ${ }^{* \#} p<0.01$ vs. experimental group.

muscle development [16]. Preliminary reports of GLUT expression in muscle biopsies from insulin-resistant subjects showed that GLUT-3 mRNA was low and GLUT-1 mRNA was increased compared with that of normal control subjects [37]. These data suggest that glucose transporter content may be an important correlate of insulin responsiveness. Therefore, the results of this study suggest that FIR stimulation may provide therapeutic improvement in a cellular environment where glucose supply is insufficient (e.g., type 2 diabetes).

Our previous study demonstrated that FIR activate mitophagy and improve mitochondrial oxidative respiration based on $\mathrm{mtD}$ NA-CN and RCR [4]. Herein, it was confirmed that both parameters increased under high and low glucose conditions following FIR treatment compared to non-treated controls (Fig. 3A, B). Determining mitochondrial ATP production and the $\Delta \Psi_{\mathrm{m}}$ allows for an assessment of the functional state of mitochondria $[26,38,39]$. The RCR per mtDNA-CN ratio increased significantly $(\mathrm{p}<0.05)$, as well as the $\Delta \Psi_{\mathrm{m}}$, following $30 \%$ BMCF treatment under 5.5 $\mathrm{mM}$ glucose when compared with that of $25 \mathrm{mM}$ glucose (Fig. $3 \mathrm{~B}-\mathrm{D})$. The change in $\Delta \Psi \mathrm{m}$ and mass is related to mitochondrial energy metabolism activity and/or mitochondrial biogenesis. Biogenesis of mitochondria, particularly under stress conditions, is often reflected by an increase in their mass [40]. Genetic downmodulation of GLUT3 expression through siRNA confirmed that TMRE and NAO decreased when GLUT3 was reduced (Fig. $4 \mathrm{~A}-\mathrm{D})$, demonstrating that the FIR effect on skeletal muscle cells persisted even after $72 \mathrm{~h}$, and that $\Delta \Psi_{\mathrm{m}}$ and mitochondrial mass were reduced upon GLUT3 loss. PGC-1a is the master regulator linking external physiological stimuli and the regulation of mito- chondrial viability [41], functioning as a good indicator of mitochondrial biogenesis. Of note, no significant change was observed in the expression of Pgc-1a following 30\% BMCF for $24 \mathrm{~h}$ (Fig. $3 \mathrm{E}$ ), whereas it was increased in both the control and the GLUT3 knock-down cells following 30\% BMCF for 72 h (Fig. 4E). Thus, these findings suggest that the upregulation of mitochondrial energy metabolism by FIR is greater after $72 \mathrm{~h}$ at low glucose levels and that GLUT3 is associated with mitochondrial biogenesis. Several studies have shown that the occurrence of diabetes is closely related to mitochondrial dysfunction $[42,43]$. Mitochondrial biogenesis plays an important role in maintaining mitochondrial numbers, cell renewal, adapting to cell damage, and the demand for energy supply [44]. Thus, the results of these experiments suggest that FIR can promote mitochondrial biosynthesis in a low glucose environment.

Altogether, this study highlights the therapeutic potential of FIR for the treatment of cellular insulin resistance, which leads to glucose deficiency and conditions such as degenerative disease or type 2 diabetes, potentially owing to decreased mitochondrial function. Additional studies are warranted to explore the exact transport pathway and the stimulatory mechanism of glucose involved in FIR-mediated improvement of mitochondrial biogenesis at low glucose conditions.

\section{ACKNOWLEDGEMENTS}

This research was supported by the Basic Science Research Program through the National Research Foundation of Korea 
(NRF), funded by the Ministry of Education (grant number: 2017R1D1A1B06035273) and Chung-Ang University Research Grants in 2016.

\section{CONFLICTS OF INTEREST}

The authors declare no conflicts of interest.

\section{SUPPLEMENTARY MATERIALS}

Supplementary data including one table and one figure can be found with this article online at https://doi.org/10.4196/ kjpp.2021.25.2.167.

\section{REFERENCES}

1. Vatansever F, Hamblin MR. Far infrared radiation (FIR): its biological effects and medical applications. Photonics Lasers Med. 2012;4:255-266.

2. Inoué S, Kabaya M. Biological activities caused by far-infrared radiation. Int J Biometeorol. 1989;33:145-150.

3. Rau CS, Yang JC, Jeng SF, Chen YC, Lin CJ, Wu CJ, Lu TH, Hsieh $\mathrm{CH}$. Far-infrared radiation promotes angiogenesis in human microvascular endothelial cells via extracellular signal-regulated kinase activation. Photochem Photobiol. 2011;87:441-446.

4. Lee D, Kim YW, Kim JH, Yang M, Bae H, Lim I, Bang H, Go KC, Yang GW, Rho YH, Park HS, Park EH, Ko JH. Improvement characteristics of bio-active materials coated fabric on rat muscular mitochondria. Korean J Physiol Pharmacol. 2015;19:283-289.

5. Brunmair B, Staniek K, Dörig J, Szöcs Z, Stadlbauer K, Marian V, Gras F, Anderwald C, Nohl H, Waldhäusl W, Fürnsinn C. Activation of PPAR-delta in isolated rat skeletal muscle switches fuel preference from glucose to fatty acids. Diabetologia. 2006;49:2713-2722.

6. Reddy PH. Role of mitochondria in neurodegenerative diseases: mitochondria as a therapeutic target in Alzheimer's disease. CNS Spectr. 2009;14(8 Suppl 7):8-13; discussion 16-18.

7. Kirkinezos IG, Moraes CT. Reactive oxygen species and mitochondrial diseases. Semin Cell Dev Biol. 2001;12:449-457.

8. Wallace DC. Why do we still have a maternally inherited mitochondrial DNA? Insights from evolutionary medicine. Annu Rev Biochem. 2007;76:781-821.

9. Rocha M, Apostolova N, Diaz-Rua R, Muntane J, Victor VM. Mitochondria and T2D: role of autophagy, ER stress, and inflammasome. Trends Endocrinol Metab. 2020;31:725-741.

10. Frantz MC, Wipf P. Mitochondria as a target in treatment. Environ Mol Mutagen. 2010;51:462-475.

11. Moraes CT, Bacman SR, Williams SL. Manipulating mitochondrial genomes in the clinic: playing by different rules. Trends Cell Biol. 2014;24:209-211.

12. Carruthers A. Facilitated diffusion of glucose. Physiol Rev. 1990;70:1135-1176.

13. Khayat ZA, McCall AL, Klip A. Unique mechanism of GLUT3 glu- cose transporter regulation by prolonged energy demand: increased protein half-life. Biochem J. 1998;333(Pt 3):713-718.

14. Weijers RNM. Membrane flexibility and cellular energy management in type 2 diabetes, gestational diabetes, and obesity. EMJ Diabet. 2014;2:65-72.

15. Ancey PB, Contat C, Meylan E. Glucose transporters in cancer - from tumor cells to the tumor microenvironment. FEBS J. 2018;285:2926-2943.

16. Bilan PJ, Mitsumoto Y, Maher F, Simpson IA, Klip A. Detection of the GLUT3 facilitative glucose transporter in rat L6 muscle cells: regulation by cellular differentiation, insulin and insulin-like growth factor-I. Biochem Biophys Res Commun. 1992;186:11291137.

17. Yaffe D. Retention of differentiation potentialities during prolonged cultivation of myogenic cells. Proc Natl Acad Sci U S A. 1968;61:477483.

18. Klip A, Li G, Logan WJ. Induction of sugar uptake response to insulin by serum depletion in fusing L6 myoblasts. Am J Physiol. 1984;247(3 Pt 1):E291-E296.

19. Ziel FH, Venkatesan N, Davidson MB. Glucose transport is rate limiting for skeletal muscle glucose metabolism in normal and STZinduced diabetic rats. Diabetes. 1988;37:885-890.

20. Furler SM, Jenkins AB, Storlien LH, Kraegen EW. In vivo location of the rate-limiting step of hexose uptake in muscle and brain tissue of rats. Am J Physiol. 1991;261(3 Pt 1):E337-E347.

21. Webb GC, Akbar MS, Zhao C, Steiner DF. Expression profiling of pancreatic beta cells: glucose regulation of secretory and metabolic pathway genes. Proc Natl Acad Sci U S A. 2000;97:5773-5778.

22. Kichenbrand C, Grossin L, Menu P, Moby V. Behaviour of human dental pulp stem cell in high glucose condition: impact on proliferation and osteogenic differentiation. Arch Oral Biol. 2020;118:104859.

23. Lee D, Seo Y, Kim YW, Kim S, Bae H, Choi J, Lim I, Bang H, Kim $\mathrm{JH}, \mathrm{Ko} \mathrm{JH}$. Far-infrared radiation stimulates platelet-derived growth factor mediated skeletal muscle cell migration through extracellular matrix-integrin signaling. Korean J Physiol Pharmacol. 2019;23:141150.

24. Livak KJ, Schmittgen TD. Analysis of relative gene expression data using real-time quantitative PCR and the 2(-Delta Delta C(T)) Method. Methods. 2001;25:402-408.

25. Frezza C, Cipolat S, Scorrano L. Organelle isolation: functional mitochondria from mouse liver, muscle and cultured fibroblasts. Nat Protoc. 2007;2:287-295.

26. Zhao RZ, Jiang S, Zhang L, Yu ZB. Mitochondrial electron transport chain, ROS generation and uncoupling (Review). Int J Mol Med. 2019;44:3-15.

27. Scaduto RC Jr, Grotyohann LW. Measurement of mitochondrial membrane potential using fluorescent rhodamine derivatives. Biophys J. 1999;76(1 Pt 1):469-477.

28. Jeong SH, Kim HK, Song IS, Noh SJ, Marquez J, Ko KS, Rhee BD, Kim N, Mishchenko NP, Fedoreyev SA, Stonik VA, Han J. Echinochrome a increases mitochondrial mass and function by modulating mitochondrial biogenesis regulatory genes. Mar Drugs. 2014;12:4602-4615.

29. Roels J, Vernaillen F, Kremer A, Gonçalves A, Aelterman J, Luong HQ, Goossens B, Philips W, Lippens S, Saeys Y. An interactive ImageJ plugin for semi-automated image denoising in electron microscopy. Nat Commun. 2020;11:771. 
30. Weisová P, Concannon CG, Devocelle M, Prehn JH, Ward MW. Regulation of glucose transporter 3 surface expression by the AMPactivated protein kinase mediates tolerance to glutamate excitation in neurons. J Neurosci. 2009;29:2997-3008.

31. Navale AM, Paranjape AN. Glucose transporters: physiological and pathological roles. Biophys Rev. 2016;8:5-9.

32. Evans PL, McMillin SL, Weyrauch LA, Witczak CA. Regulation of skeletal muscle glucose transport and glucose metabolism by exercise training. Nutrients. 2019;11:2432.

33. Zhou B, Tian R. Mitochondrial dysfunction in pathophysiology of heart failure. J Clin Invest. 2018;128:3716-3726.

34. Maher F, Vannucci SJ, Simpson IA. Glucose transporter proteins in brain. FASEB J. 1994;8:1003-1011.

35. Guillet-Deniau I, Leturque A, Girard J. Expression and cellular localization of glucose transporters (GLUT1, GLUT3, GLUT4) during differentiation of myogenic cells isolated from rat foetuses. J Cell Sci. 1994;107(Pt 3):487-496.

36. Tsakiridis T, Vranic M, Klip A. Phosphatidylinositol 3-kinase and the actin network are not required for the stimulation of glucose transport caused by mitochondrial uncoupling: comparison with insulin action. Biochem J. 1995;309(Pt 1):1-5.

37. Stuart CA, Wen G, Thompson EA. Abnormal expression and distribution of glucose transporters in muscle of insulin resistant subjects. Diabetes. 1999;48:SA262.

38. Clay Montier LL, Deng JJ, Bai Y. Number matters: control of mammalian mitochondrial DNA copy number. J Genet Genomics.
2009;36:125-131.

39. Nicholls DG. Mitochondrial function and dysfunction in the cell: its relevance to aging and aging-related disease. Int J Biochem Cell Biol. 2002;34:1372-1381.

40. Walczak J, Malińska D, Drabik K, Michalska B, Prill M, Johne S, Luettich K, Szymański J, Peitsch MC, Hoeng J, Duszyński J, Więckowski MR, van der Toorn M, Szczepanowska J. Mitochondrial network and biogenesis in response to short and long-term exposure of human BEAS-2B cells to aerosol extracts from the Tobacco Heating System 2.2. Cell Physiol Biochem. 2020;54:230-251.

41. Dorn GW 2nd, Vega RB, Kelly DP. Mitochondrial biogenesis and dynamics in the developing and diseased heart. Genes Dev. 2015;29:1981-1991.

42. Yuzefovych LV, Musiyenko SI, Wilson GL, Rachek LI. Mitochondrial DNA damage and dysfunction, and oxidative stress are associated with endoplasmic reticulum stress, protein degradation and apoptosis in high fat diet-induced insulin resistance mice. PLOS One. 2013;8:e54059.

43. Ramalingam L, Menikdiwela K, LeMieux M, Dufour JM, Kaur G, Kalupahana N, Moustaid-Moussa N. The renin angiotensin system, oxidative stress and mitochondrial function in obesity and insulin resistance. Biochim Biophys Acta Mol Basis Dis. 2017;1863:11061114.

44. Piantadosi CA, Suliman HB. Redox regulation of mitochondrial biogenesis. Free Radic Biol Med. 2012;53:2043-2053. 